\title{
Article
}

\section{Modern Methods for Aircraft Power and Propulsion}

\author{
Relly Victoria Petrescu 1, Raffaella Aversa ${ }^{2}$, Antonio Apicella ${ }^{2}$, Florian Ion T. Petrescu 1,* \\ 1 IFToMM-ARoTMM, Bucharest Polytechnic University, Bucharest, (CE), Romania \\ 2 Advanced Material Lab, Department of Architecture and Industrial Design, \\ The Second University of Naples, 81031 Aversa (CE), Italy \\ * Correspondence: florian.petrescu@upb.ro; Tel.: +(4) 0724040348
}

\begin{abstract}
Even though the current classic aerospace propulsion methods are greatly improved, some of the most modern methods have already been introduced, among which the propulsion with electric motors. Energy can be obtained from hydrogen burners, honeycomb burners to protect the burning of hydrogen that burns 10 times faster than conventional oil fuels or alcohols. Hydrogen storage is also done in honeycomb cell reservoirs. Getting solar photovoltaic power even during flight is not yet profitable or efficient, but it can be proposed in the future for lighter and/or spacecraft. A great desire is to dismantle water in hydrogen and oxygen directly on the aircraft, so the stored fuel is actually water and the one actually used is the hydrogen removed from the water. In this case, there is no need for hydrogen storage. And other modern methods of propulsion and energy acquisition are briefly presented in the paper.
\end{abstract}

Keywords: aerospace propulsion; electric motors; hydrogen burners; hydrogen storage; honeycomb cell reservoirs; solar photovoltaic power; modern propulsions.

\section{Introduction}

Flight is so important to mankind that any type of fuel used from the time, even long before the planet's oil reserves are exhausted, is welcome.

Under current conditions, testing and introducing a modernized gas turbine in aviation would be justified because huge reserves of deep-sea shale have been discovered, which today can be exploited thanks to advanced technologies, and gas is already provided for at least a thousand years even if oil reserves are getting smaller).

Commercial aircraft businesses are booming, using all of the market's seizing methods. Airbus delivered 635 commercial aircraft in 2015, while Boeing sales reached 762 in the same year. In recent years, the two giant aircraft manufacturers have honored about 1,800 orders each year, and are still getting delivery orders for orders which already exceeds 12,000 aircraft and the order figure is still on the rise because commercial flights are in a period of great expansion to the detriment of even other types of transport, not just because we live the century of speed and the world is rushing out of what more, but also because this mode of transport proved to be the fastest, safest and most reliable.

Considering the current production rate, it will take about ten years to recover delays to existing orders.

Given the fact that an aircraft can be used for decades without problems it is curious how all airline users are rushing to renew their commercial fleets, the real justification for this being precisely the upgrades of new aircraft with increased comfort, a lot of flight safety, but especially new turbo engines based on state-of-the-art technologies. The new turbo engines produced and marketed are quieter and more fuel-efficient compared to previous generations, and ultimately a rapid response to the energy crisis and the further depletion of oil reserves is also fuel economy. Already the fuel consumption of new aircraft turbo engines is lower by $15 \%$ (and promises by the specialists for a $20 \%$ future discount), and for an airline with major direct operating costs, this low consumption quickly compensates for the new acquisitions aircraft, thus justifying the change of aircraft well before their wear. 
The construction of engines for commercial aircraft equipped with turbojet engines is the largest market segment for the gas turbine industry, but it is far from being the only one. The FI financial report shows that the global value of gas turbine production was \$ 81.4 billion in 2014 and \$ 63 billion in 2015. To have a complete picture of aviation gas turbine engine orders in 2015 for example, $\$ 8.1$ billion was their production for the military segment, and $\$ 54.9$ billion was spent on the commercial aviation engines.

Both GE (General Electric) and P \& W (Pratt \& Whitney) have new high performance engines on the aircraft market, with a GE turbocharger called LEAP, abbreviated from the Leading Edge Aviation Propulsion, with a larger compression ratio, a composite fan carbon fiber with a larger diameter, engines for which there are already 10000 orders. LEAP is the first gas turbine engine that uses ceramic matrix composite materials along the gas path. Typical fiber materials include silicon carbide and are mainly used as ceramic matrix components (CMC = Ceramic Matrix Composites), a matrix that is embedded between fibers. Besides other advantages offered by composite materials, a big advantage is that of a two-thirds reduction in weight compared to conventional systems, and their high temperature resistance is even greater than the metal alloys they replace. GE extends the application of CMCs to its next-generation GE9X engine, 100,000 pounds now being developed for the Boeing 777X and scheduled to be operational in 2020. It will include in a first stage combustion tubes, high turbine stators pressure and coatings of CMC.

Pratt \& Whitney has developed a new gas turbine engine since 1980, which has now been upgraded to a turbocharger with a gearshift, which has a planetary gear, able to reduce fan speed, thus leading to a much lower noise level the final engine, and a real fuel economy. The first user of such an engine (PW1100-G) is Lufthansa, which flies with the Airbus A320neo passenger aircraft between German cities. The initial reports indicate that the turbo-compressors meet the fuel economy requirements perfectly and are also much quieter [1-2].

\section{Materials and Methods}

When there will be no more oil and gas, hydrogen will become a major fuel as an inexhaustible fuel, but it can be introduced long before, just to have another source of fuel than the classic fuel, another variant that will guarantee the future and also diminish of consumption of classical fuels that are endangered anyway.

MA hydrogen powered aircraft is an aircraft that uses hydrogen fuel as a source of energy. Hydrogen can be burnt in a reaction engine or other type of internal combustion engine or can be used to provide a combustion cell to generate electrical power to propel a propeller.

Unlike most aircraft using fuel storage wings, hydrogen planes are typically designed with hydrogen-based liquid fuel transported inside the fuselage to minimize the surface and reduce boil-off [3].

According to research from Pennsylvania State University in 2006, large commercial aircraft could be built by 2020, but "probably will not go into service until 2040."

The European Union's research project, in collaboration with Airbus and 34 other partner companies, called CRYOPLANE, assessed the technical feasibility, safety, environmental compatibility and economic viability of using liquid hydrogen as aviation fuel [4].

Hydrogen also has the great advantage of being easily extracted from the water, and by burning it produces water back, so it is made by its use, a natural circuit without the known pollution from classical fossil fuels.

The great advantage of using such a system is that we will be prepared to use hydrogen straight away from the water without the need for its storage. This will be possible when modern extraction systems (water dissociation in its components oxygen and hydrogen) will be developed with the use of a lower amount of energy than that obtained by burning hydrogen. This will allow the use of water as an energy storage device. Modern water dissociation systems use nanocells filters by which water is pressed to break, platinum or other noble metal catalysts, and an ultraviolet radiation environment tuned to certain intensity [5]. 
Special photovoltaic cells built by NASA specialists (who are able to attract a large amount of stars energy due to their construction) will be useful in the future of spacecraft as an additional source of energy or could be used to produce energy in the bases we will install in the future on other planets. However, due to the high volume of these power systems, they cannot be fitted to a modern passenger aircraft. For this reason, future aircraft that want electric motors will still need an energy source, just like spacecraft, where the photovoltaic source is only a secondary one. Today in spacecraft, nuclear fission reactors are used as the main energy source, and most often their fuel is thorium and not uranium (used to the stationary nuclear power plants).

Apart from gas and hydrogen complementary to petroleum fuels, it is necessary to experiment with the introduction of modern propulsion systems with the acceleration of elementary particles so that the jet has a very high impulse. Such propulsion systems, either with accelerated positive ions or high-energy gamma-photons, are absolutely necessary for spacecraft to leave behind the classical systems that have practically been the propulsion of "space carts", yet having the merit of pioneers in the space field at that weather [6-25].

Modern propulsion means usually use positive ions accelerated most frequently with a circular particle accelerator [26].

It should be noted that particle accelerators are today the future of the advanced technologies of the planet, they are necessary for obtaining massive concentrated energy, including for spacecraft, but here they are also used to accelerate the particles ejected in order to achieve the propulsion of the ships. Used relatively recently in physics, medicine, and increasingly in many fields, stationary particle accelerators will need to be adapted as mobile accelerators, spacecraft related, either in order to produce nuclear fusion energy or to achieve the accelerated final jet of elementary particles that will virtually achieve propulsion of the ship. And for these reasons, particle accelerators that have developed a lot over the last 50 years need massive funding to their developing and to cope with new space and energy challenges, particularly those in fusion nuclear power [11].

A positive (commonly circular) ion accelerator has the great advantage that it can accelerate the ions to unprecedented elevations, increasing their energy and impulse very much. Electrons cannot be accelerated so much because they leave the accelerator uncontrolled, or they will lose energy by photon emission (typically gamma). A linear accelerator could increase the energy of the electrons without losing them, but the space needed for such an accelerator that should be very long representing a great inconvenience for a spacecraft, and often even for stationary accelerators which for this reason is preferred to be circular where the accelerated particle can pass many times on the same path to increase its energy and impulse.

Lasers or synchrotrons that produce light energy have lower dimensional advantages and the fact that some lasers can produce much more pulses per second compared to particle accelerators, thus boosting the impulse due to a large number of pulses generated in one second. If a modern circular accelerator could generate a pulse per second and perhaps will hasten the pace in the near future, there are laser already able to donate $10^{15}$ pulses per second [11].

The today ionic engine (ionic propellant) has 2 major advantages (a) and 2 disadvantages (b) compared to chemical propulsion; (a) the impulse and energy per unit of fuel used are much higher; 1 - Increasing the impulse generates a higher speed (speed so that we can go for longer distances in a short time); 2 - High energy reduces fuel consumption and increases the autonomy of the ship; (b) force generation and acceleration are very low; one cannot overcome the resistance forces at moving through the atmosphere and have not the chance to overcome gravitational forces - the ship will not leave a planet using actual ionic propulsion (requires an extra engine). The acceleration speed of the ship is possible, but only with very low acceleration. Increasing multiple energies (and also pulse) can reach the required forces and accelerations (Increase will have to be very high, $100 \mathrm{PeV}-1000$ $\mathrm{PeV}$ ). Increasing particle energy can be done with circular or modern linear accelerators. The increase in particle energy will be enormous and, in addition, the accelerated particulate stream will have to increase (and the torque diameter, if sufficient flow increases, the required energy will be 10 GeV-10 TeV) [11, 23-24, 26]. 
One can still improve the efficiency of 10-50 times if one uses pulses of positive ions accelerated in a cyclotron mounted on the ship; the efficiency can easily grow for 1000 times if the positive ions will be accelerated in a high energy synchrotron, synchrocyclotron or isochronous cyclotron (1-100 $\mathrm{GeV}$ ). The future (ionic) engine will have mandatory a circular particle accelerator (high or very high energy). We can thus increase the speed and autonomy of the ship using a less quantity of fuel and power. It can use synchrotron radiation (synchrotron light, high-intensity beams), like high intensity (X-ray or Gamma ray) radiation, as well. In this case, will be a beam engine (not an ionic engine), it'll use only the power (energy, which can be solar energy, nuclear energy, or both) and so we will remove the fuel. A linear particle accelerator (also called a LINAC) is an electrical device for the acceleration of subatomic particles. This sort of particle accelerator has many applications. It used recently as to an injector into a higher energy synchrotron at a dedicated experimental particle physics laboratory. In this, the big classic synchrotron is reduced to a ring surface (magnetic core) [11]. As we are talking a lot today about the electric motors used in the aerospace industry, it must be made the specification that they themselves represent only a means of propulsion, not and an energy one and for this reason a large aircraft it cannot provide the electric power that is required for the engines only by capturing it through photovoltaic cells, so the ship will need an energy source. Battery storage allows only a small autonomy for a light aircraft, so for passenger aircraft, electrically propelled it will be necessary to burn classic fuels, gas or hydrogen into the cells to get the thermal energy then converted into the electric power of the ship. For this reason, propulsion with electric motors should be developed along with the hydrogen system. The main objective of this paper is to specify how to design and use elementary particle accelerators to effectively achieve modern propulsion of an aircraft.

As one has already shown the main energy source of today used in the aerospace, remain the nuclear reactor on the fission. But we need a stronger energy source and provide more energy for a much longer period of time, so the ship's autonomy will increase significantly, which is why the fusion reactor must be developed and introduced.

Every elemental mobile particle possesses kinetic energy (relationship 1) composed of two components: the kinetic energy of translational motion and the kinetic energy of the rotating motion.

$$
E_{c}=\frac{1}{2} m \cdot v^{2}+\frac{1}{2} J \cdot \omega^{2}
$$

The well-known Lorentz relationship (2) is used to determine the mass of the moving particle at a high displacement velocity.

$$
m=\frac{m_{0} \cdot c}{\sqrt{c^{2}-v^{2}}}
$$

Mechanical moment of inertia (mass) of the particle (around its axis of rotation) is determined by the relationship (3).

$$
J=\frac{2}{5} m \cdot R^{2}
$$

This is the mass moment of inertia of a sphere (see Fig. 1).

Using forms 2 and 3 the expression 1 takes the forms 4 .

$$
\left\{\begin{array}{l}
E_{c}=\frac{1}{2} m \cdot v^{2}+\frac{1}{2} \cdot \frac{2}{5} \cdot m \cdot R^{2} \cdot \omega^{2} \\
E_{c}=\frac{1}{2} \frac{m_{0} \cdot c \cdot v^{2}}{\sqrt{c^{2}-v^{2}}}+\frac{1}{2} \cdot \frac{2}{5} \cdot \frac{m_{0} \cdot c \cdot R^{2}}{\sqrt{c^{2}-v^{2}}} \cdot \omega^{2}
\end{array}\right.
$$

The relationship (5) is used to express the elementary particle impulse.

$$
p=m \cdot v=\frac{m_{0} \cdot c \cdot v}{\sqrt{c^{2}-v^{2}}}
$$

The wavelength associated with the particle can be determined by the relationship (6) (according to Louis de Broglie the impulse is the one which is conserved). 


$$
\lambda=\frac{h}{p}=\frac{h \cdot \sqrt{c^{2}-v^{2}}}{m_{0} \cdot c \cdot v}
$$

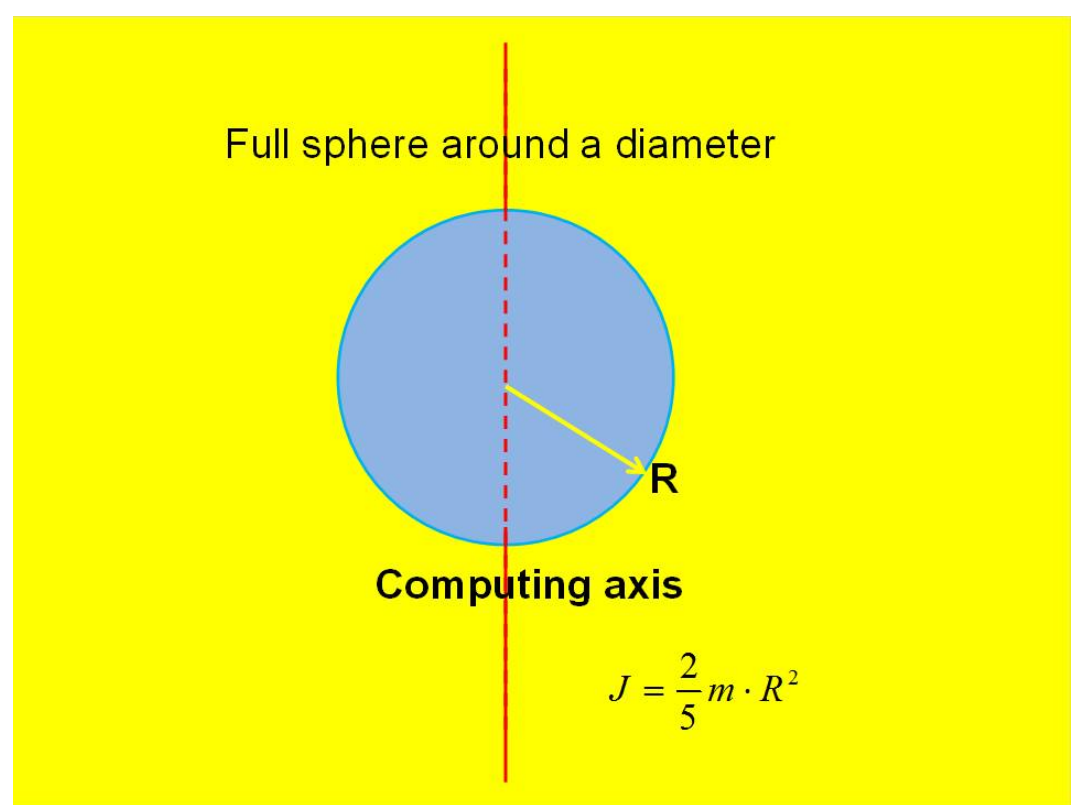

Fig. 1. Mass moment of inertia to a full sphere determined around a diameter

The particle wave frequency associated with the particle is determined by the relationship (7).

$$
\gamma=\frac{c}{\lambda}=\frac{c \cdot m_{0} \cdot c \cdot v}{h \cdot \sqrt{c^{2}-v^{2}}}=\frac{m_{0} \cdot c^{2} \cdot v}{h \cdot \sqrt{c^{2}-v^{2}}}
$$

Expressions (8) generate the angular velocity of the particle and its square.

$$
\left\{\begin{array}{l}
\omega=2 \pi \gamma=\frac{2 \pi \cdot m_{0} \cdot c^{2} \cdot v}{h \cdot \sqrt{c^{2}-v^{2}}} \\
\omega^{2}=\frac{4 \pi^{2} \cdot m_{0}^{2} \cdot c^{4} \cdot v^{2}}{h^{2} \cdot\left(c^{2}-v^{2}\right)}
\end{array}\right.
$$

Using expression (8) the relationship (4) takes the forms (9).

$$
\left\{\begin{array}{l}
E_{c}=\frac{1}{2} \frac{m_{0} \cdot c \cdot v^{2}}{\sqrt{c^{2}-v^{2}}}+\frac{1}{2} \cdot \frac{2}{5} \cdot \frac{m_{0} \cdot c \cdot R^{2}}{\sqrt{c^{2}-v^{2}}} \cdot \frac{4 \pi^{2} \cdot m_{0}^{2} \cdot c^{4} \cdot v^{2}}{h^{2} \cdot\left(c^{2}-v^{2}\right)} \\
E_{c}=\frac{1}{2} \frac{m_{0} \cdot c \cdot v^{2}}{\sqrt{c^{2}-v^{2}}} \cdot\left[1+\frac{8}{5} R^{2} \cdot \pi^{2} \frac{m_{0}^{2} \cdot c^{4}}{h^{2} \cdot\left(c^{2}-v^{2}\right)}\right]
\end{array}\right.
$$

On the other hand, the kinetic energy of the moving particles can also be obtained by means of the expression (10), where from the total energy of the moving particle the rest energy of the particle is reduced.

$$
E_{c}=E-E_{0}=m \cdot c^{2}-m_{0} \cdot c^{2}=m_{0} \cdot c^{2} \cdot \frac{c-\sqrt{c^{2}-v^{2}}}{\sqrt{c^{2}-v^{2}}}
$$

By identifying relationships (9) and (10) obtains the expressions (11) able to determine the radius of an elementary mobile particle. 


$$
\begin{aligned}
& {\left[\frac{1}{2} \frac{m_{0} \cdot c \cdot v^{2}}{\sqrt{c^{2}-v^{2}}} \cdot\left[1+\frac{8}{5} R^{2} \cdot \pi^{2} \frac{m_{0}^{2} \cdot c^{4}}{h^{2} \cdot\left(c^{2}-v^{2}\right)}\right]=m_{0} \cdot c^{2} \cdot \frac{c-\sqrt{c^{2}-v^{2}}}{\sqrt{c^{2}-v^{2}}}\right.} \\
& R=\sqrt{\frac{10}{8}} \cdot \frac{h}{\pi \cdot m_{0} \cdot c^{2}} \cdot \frac{\sqrt{c^{2}-v^{2}} \cdot \sqrt{c^{2}-\frac{v^{2}}{2}-c \cdot \sqrt{c^{2}-v^{2}}}}{v} \\
& R=\sqrt{\frac{10}{8}} \cdot \frac{h \cdot \sqrt{c^{2}-v^{2}} \cdot \sqrt{c^{2}-\frac{v^{2}}{2}-c \cdot \sqrt{c^{2}-v^{2}}}}{\pi \cdot m_{0} \cdot c^{2} \cdot v}
\end{aligned}
$$

It is known and the expression of potential energy between two adjacent particles (electrostatic potential energy), which should be the energy with that a particle needs to be accelerated before to collide (relationships 12, Fig. 2, [6]). This electrostatic potential energy must be the same as the (final) kinetic energy of motion translational of accelerated particle $\mathrm{Ep}=1 / 2 \mathrm{mv}^{2}$.

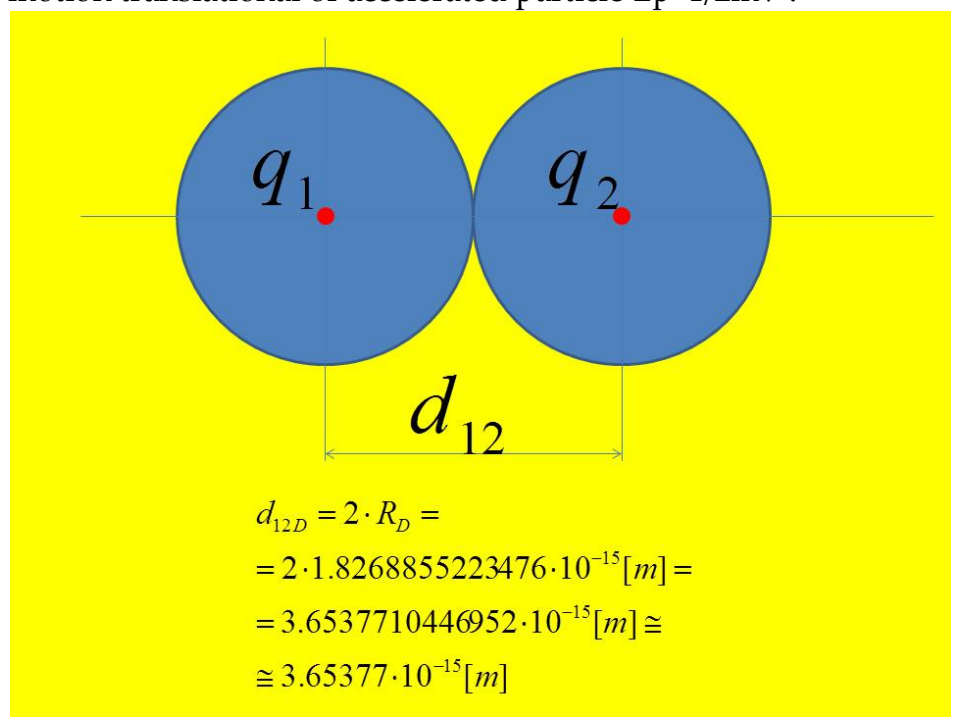

Fig. 2. Two adjacent particles of Deuterium

$$
\left\{\begin{array}{l}
E_{p}=\frac{1}{4 \pi \cdot \varepsilon_{0}} \cdot \frac{q_{1} \cdot q_{2}}{d_{12}}=\frac{q_{1} \cdot q_{2}}{8 \pi \cdot \varepsilon_{0} \cdot R} \\
E_{p}=\frac{1}{2} m \cdot v^{2}
\end{array}\right.
$$

The radius of stationary deuterium was determined in Figure 2 based on the relationship (13).

$$
\left\{\begin{array}{l}
R_{D}=r_{0} \cdot A^{1 / 3} \\
r_{0}=1,45 E-15[\mathrm{~m}] \text { the average radius } \\
\text { of a nucleon fixed } \\
\mathrm{A}=\text { the atomic mass }
\end{array}\right.
$$

With the expression (11), the radius of a Deuteron or any other moving particle can now be obtained with great accuracy depending on its displacement velocity $\mathrm{v}$. The kinetic energy produced by the rotational movement of the particle is expressed by the relationship (14).

$$
E_{c \omega}=\frac{1}{2} \cdot \frac{2}{5} \cdot m \cdot R^{2} \cdot \omega^{2}=\frac{2}{10} \cdot m \cdot R^{2} \cdot \frac{4 \pi^{2} \cdot m^{2} \cdot c^{2} \cdot v^{2}}{h^{2}}=\frac{8}{10} \frac{\pi^{2} \cdot m^{3} \cdot c^{2} \cdot v^{2} \cdot R^{2}}{h^{2}}
$$


In order to start the two-particle fusion reaction, they must be brought together by overcoming the electrostatically-energy between the two charged particles each one positive (energy expressed by the relationship 12) with the kinetic energy of the linear motion particles $E c=1 / 2 \mathrm{mv}^{2}$. For this reason, the radius of a particle (in motion) can now be determined from the relationship (12), with the expression (15).

$$
R=\frac{q_{1} \cdot q_{2}}{4 \pi \cdot \varepsilon_{0} \cdot m \cdot v^{2}}
$$

Using the relationship (15), expression (14) takes the form (16).

$$
E_{c \omega}=\frac{\left(q_{1} \cdot q_{2}\right)^{2} \cdot c^{2} \cdot m}{20 h^{2} \cdot \varepsilon_{0}^{2} \cdot v^{2}}
$$

The kinetic energy due to the particle rotation movement (already expressed through relationship 16) can now also be written by the expression (17). From the total energy of the moving particles, the kinetic energy produced by the particle translation movement and the resting energy of the particle (potential energy) is decreased.

$$
E_{c \omega}=m \cdot c^{2}-\frac{1}{2} m \cdot v^{2}-m_{0} \cdot c^{2}
$$

Equaling expressions (16) and (17) obtains the equation (18), in $\mathrm{v}^{2}$.

$$
m \cdot c^{2}-\frac{1}{2} m \cdot v^{2}-m_{0} \cdot c^{2}=\frac{\left(q_{1} \cdot q_{2}\right)^{2} \cdot c^{2} \cdot m}{20 h^{2} \cdot \varepsilon_{0}^{2} \cdot v^{2}}
$$

Equation (18) takes the shapes (19-26), thus being arranged to solve it.

$$
\begin{aligned}
& m c^{2}-m_{0} c^{2}=\frac{\left(q_{1} q_{2}\right)^{2} c^{2} m+10 m v^{4} h^{2} \varepsilon_{0}^{2}}{20 h^{2} \cdot \varepsilon_{0}^{2} \cdot v^{2}} \\
& \frac{m_{0} c^{2}\left(c-\sqrt{c^{2}-v^{2}}\right)}{\sqrt{c^{2}-v^{2}}}=\frac{c m_{0}\left[\left(q_{1} q_{2}\right)^{2} c^{2}+10 h^{2} \varepsilon_{0}^{2} v^{4}\right]}{20 h^{2} \cdot \varepsilon_{0}^{2} \cdot v^{2} \sqrt{c^{2}-v^{2}}} \\
& 20 h^{2} \varepsilon_{0}^{2} v^{2}\left(c^{2}-c \sqrt{c^{2}-v^{2}}\right)=\left(q_{1} q_{2}\right)^{2} c^{2}+10 h^{2} \varepsilon_{0}^{2} v^{4} \\
& 20 h^{2} \varepsilon_{0}^{2} v^{2} c^{2}-20 h^{2} \varepsilon_{0}^{2} v^{2} c \sqrt{c^{2}-v^{2}}=\left(q_{1} q_{2}\right)^{2} c^{2}+10 h^{2} \varepsilon_{0}^{2} v^{4} \\
& 20 h^{2} \varepsilon_{0}^{2} v^{2} c^{2}-\left(q_{1} q_{2}\right)^{2} c^{2}-10 h^{2} \varepsilon_{0}^{2} v^{4}=20 h^{2} \varepsilon_{0}^{2} v^{2} c \sqrt{c^{2}-v^{2}} \\
& \left(20 h^{2} \varepsilon_{0}^{2} v^{2} c^{2}-\left(q_{1} q_{2}\right)^{2} c^{2}-10 h^{2} \varepsilon_{0}^{2} v^{4}\right)^{2}=400 h^{4} \varepsilon_{0}^{4} v^{4} c^{2}\left(c^{2}-v^{2}\right) \\
& \left\{\begin{array}{l}
100 h^{4} \varepsilon_{0}^{4} x^{4}+200 h^{4} \varepsilon_{0}^{4} c^{2} x^{3}+20 h^{2} \varepsilon_{0}^{2} c^{2}\left(q_{1} q_{2}\right)^{2} x^{2}-40 h^{2} \varepsilon_{0}^{2} c^{4}\left(q_{1} q_{2}\right)^{2} x+\left(q_{1} q_{2}\right)^{4} c^{4}=0 \\
\text { with } \quad x=v^{2}
\end{array}\right. \\
& \left\{\begin{array}{l}
x^{4}+a x^{3}+b x^{2}-c x+d=0 \\
a=2 c^{2} ; \quad b=\frac{c^{2}\left(q_{1} q_{2}\right)^{2}}{5 h^{2} \varepsilon_{0}^{2}} ; \quad c=\frac{2 c^{4}\left(q_{1} q_{2}\right)^{2}}{5 h^{2} \varepsilon_{0}^{2}} ; \quad d=\frac{c^{4}\left(q_{1} q_{2}\right)^{4}}{100 h^{4} \varepsilon_{0}^{4}}
\end{array}\right.
\end{aligned}
$$

By solving the equation (26) in v2 the v value for accelerated particle velocity is obtained, the velocity required to start the fusion reaction between the elementary particles (expression 27). 
This is the speed that must be imprinted on the elementary particles to cause them to fuse together.

Obviously, to accelerate the elementary particles (in our case those of ionized deuterium, i.e. deuterons), it is necessary to accelerate them in circular particle accelerators, whether the reaction will be used in the nuclear fusion on stationary reactors or some mounted on an aircraft.

$$
\left\{\begin{array}{l}
v^{2}=4.784 \mathrm{E}+11\left[\mathrm{~m}^{2} / \mathrm{s}^{2}\right] \\
v=691664.8602[\mathrm{~m} / \mathrm{s}] \\
\beta=\mathrm{v} / \mathrm{c}=0.00230708
\end{array}\right.
$$

\section{Results}

First, it is necessary to determine the required speed of the accelerated particles to start the fusion reaction when they collide (Equation 26 can be used).

This speed has the value: $\mathrm{v}=691664[\mathrm{~m} / \mathrm{s}]$

Secondly, the radius of a moving deuteron particle can now be determined with great precision using the new and original expression (28) (extracted from the final relationship of the system 11).

$$
R=\sqrt{\frac{10}{8}} \cdot \frac{h \cdot \sqrt{c^{2}-v^{2}} \cdot \sqrt{c^{2}-\frac{v^{2}}{2}-c \cdot \sqrt{c^{2}-v^{2}}}}{\pi \cdot m_{0} \cdot c^{2} \cdot v}
$$

Thirdly, the potential energy of the two adjacent deuterium particles can now be determined to enter the fusion. This is the minimal translational kinetic energy that must reach an accelerated deuterium particle to produce fusion (using form 29 of relationship 12).

$$
E_{p}=\frac{q_{1} \cdot q_{2}}{8 \pi \cdot \varepsilon_{0} \cdot R}
$$

With mo deuteron=3.34524E-27[kg] and $\mathrm{v}=691665[\mathrm{~m} / \mathrm{s}]$.

The radius of deuteron at this velocity (calculated with relationship 28) takes the below value: $\mathrm{R}_{\mathrm{D}}=1.91788 \mathrm{E}-19$ [m] (dynamic at $\mathrm{v}=0.002307088 \mathrm{c}$ ). Static $\mathrm{R}=1.827 \mathrm{E}-15$ [m].

The potential energy has now the below value:

$\mathrm{U}=\mathrm{Ep}=6.01333 \mathrm{E}-10[\mathrm{~J}]=3753521838[\mathrm{eV}]=3753521.838[\mathrm{KeV}]=3753.521838[\mathrm{MeV}]==3.75[\mathrm{GeV}]$

It is clear that it is necessary to accelerate a deuteron with a minimum of $3.76 \mathrm{GeV}$ to prepare it for the future fusion reaction and then collide these accelerated detonators to begin the real fusion process.

The expression (28) has the advantage of giving the dynamic range of a particle at any speed, except for the two limits when $\mathrm{v}=\mathrm{c}$ or $\mathrm{v}=0$, which are never touched by the particle, nor will it be able to reach the speed of light as much as it would accelerate to get closer to the value of the essence.

If $\mathrm{v}=\mathrm{c}$ the particle becomes a photon and other equations will be used in this case.

Dynamic, at low or high velocities the matter is focused.

With the new expression (28) introduced one can determine the radius of an elementary particle in movement.

$\beta$ is the ratio between $\mathrm{v}$ and $\mathrm{c}$; expression (30):

$$
\beta=\frac{v}{c}
$$

One can determine the radius of a proton in movement (table 1).

From the table 1 one can determine and the value of average radius of a proton (or neutron) $5.9779 \mathrm{E}-17[\mathrm{~m}]$, and its maximum value $9.97547 \mathrm{E}-17[\mathrm{~m}] \cong 1 \mathrm{E}-16[\mathrm{~m}]$ obtained for $\beta=0.8$. 
Table 1. The proton radius in function of $\beta$.

\begin{tabular}{|l|c|c|c|}
\hline$\beta$ & 0.000009 & 0.00002 & 0.0001 \\
\hline $\mathrm{R}[\mathrm{m}]$ & $2.68 \mathrm{E}-19$ & $2.21 \mathrm{E}-19$ & $4.43 \mathrm{E}-20$ \\
\hline & & & \\
\hline$\beta$ & 0.001 & 0.01 & 0.1 \\
\hline $\mathrm{R}[\mathrm{m}]$ & $1.66 \mathrm{E}-19$ & $1.66 \mathrm{E}-18$ & $1.65 \mathrm{E}-17$ \\
\hline & & & \\
\hline$\beta$ & 0.2 & 0.3 & 0.4 \\
\hline $\mathrm{R}[\mathrm{m}]$ & $3.29 \mathrm{E}-17$ & $4.87 \mathrm{E}-17$ & $6.36 \mathrm{E}-17$ \\
\hline & & & \\
\hline$\beta$ & 0.5 & 0.6 & 0.7 \\
\hline $\mathrm{R}[\mathrm{m}]$ & $7.71 \mathrm{E}-17$ & $8.86 \mathrm{E}-17$ & $9.69 \mathrm{E}-17$ \\
\hline & & & 0.99 \\
\hline$\beta$ & 0.8 & 0.9 & $4.06 \mathrm{E}-17$ \\
\hline $\mathrm{R}[\mathrm{m}]$ & $9.97 \mathrm{E}-17$ & $9.08 \mathrm{E}-17$ & \\
\hline & & & 0.99999 \\
\hline$\beta$ & 0.999 & 0.9999 & $1.48 \mathrm{E}-18$ \\
\hline $\mathrm{R}[\mathrm{m}]$ & $1.42 \mathrm{E}-17$ & $4.63 \mathrm{E}-18$ & \\
\hline & & & 0.99999999 \\
\hline$\beta$ & 0.999999 & 0.9999999 & \\
\hline $\mathrm{R}[\mathrm{m}]$ & $4.69 \mathrm{E}-19$ & $1.48 \mathrm{E}-19$ & $4.70 \mathrm{E}-20$ \\
\hline & & & \\
\hline & & & \\
\hline & & & \\
\hline & & & \\
\hline & & & \\
\hline & & & \\
\hline & & & \\
\hline & & & \\
\hline & & & \\
\hline & & & \\
\hline & & & \\
\hline & & & \\
\hline
\end{tabular}

When the number of nucleons increases (when the atomic mass A, the mass of the nucleus, increases) the nucleus size decreases. In a deuterium nucleus (in a deuteron), one has two nucleons (a proton and a neutron). These are the results of the new expression 28 indicating a matter compression inversely proportional to the mass (see the below values).

\section{New theory/calculation}

The kinetic energy of an elementary particle in the translational movement has the known form (31).

$$
E_{C}=\frac{1}{2} \cdot m \cdot v^{2}
$$

The classic impulse has a known form (relationship 32).

$$
K=m \cdot v
$$

If one takes into account that elementary particles move at high speeds which may be compared to the light speed being a ratio of it, it is imperative to use a more complete original relationship (33) for the impulse of an elementary particle, knowing that the impulse is the derivative of the kinetic energy in rapport with the speed of movement. This allows its calculation with high precision.

$$
p=\frac{d E_{c}}{d v}=\frac{d m}{d v} \cdot \frac{v^{2}}{2}+\frac{m}{2} \cdot \frac{d v^{2}}{d v}=\frac{m \cdot v \cdot\left(2 \cdot c^{2}-v^{2}\right)}{\left(2 \cdot c^{2}-2 \cdot v^{2}\right)}=m \cdot v \cdot \frac{2 \cdot c^{2}-v^{2}}{2 \cdot c^{2}-2 \cdot v^{2}}
$$

To obtain relationship (33), one also used formula (34) obtained by derivation Lorentz equation (35) in relation to velocity. 


$$
\begin{gathered}
\frac{d m}{d v}=\frac{m \cdot v}{c^{2}-v^{2}} \\
m=m_{0} \cdot \frac{1}{\sqrt{1-\frac{v^{2}}{c^{2}}}}=\frac{m_{0} \cdot c}{\sqrt{c^{2}-v^{2}}}
\end{gathered}
$$

To write the impulse according to the particle rest mass, one uses the Lorentz relationship (35) and the expression (33) thus acquires the forms of the system (36).

$$
\left\{\begin{array}{l}
\Rightarrow p=\frac{m_{0} \cdot c \cdot v \cdot\left(2 \cdot c^{2}-v^{2}\right)}{2 \cdot \sqrt{c^{2}-v^{2}} \cdot\left(c^{2}-v^{2}\right)}=\frac{m_{0} \cdot c \cdot v \cdot\left(2 \cdot c^{2}-v^{2}\right)}{2 \cdot\left(c^{2}-v^{2}\right)^{3 / 2}}=m_{0} \cdot v \cdot \frac{c \cdot\left(2 \cdot c^{2}-v^{2}\right)}{2 \cdot\left(c^{2}-v^{2}\right)^{3 / 2}} \\
p=m_{0} \cdot v \cdot \frac{c \cdot\left(2 \cdot c^{2}-v^{2}\right)}{2 \cdot\left(c^{2}-v^{2}\right)^{3 / 2}} \text { when } v \neq c \\
p=\frac{h}{\lambda} \text { when } v \equiv c
\end{array}\right.
$$

For accelerated positive ions no matter how near the speed of light (they can practically not touch it), the relation (37) can be used to express the impulse.

$$
p=m_{0} \cdot v \cdot \frac{c \cdot\left(2 \cdot c^{2}-v^{2}\right)}{2 \cdot\left(c^{2}-v^{2}\right)^{3 / 2}} \quad \text { when } \quad v \neq c ; v<c
$$

The total impulse of the particle jet, i.e. the impulse that will actually act on the spacecraft, can be determined by the relationship (38), where $n$ represents the number of pulses generated in one second by an ionic engine, $\mathrm{N}$ is the average number of particles per one pulse, and $\mathrm{M}$ represents the number of ionic engines operating simultaneously the ship.

$$
k=M \cdot n \cdot N \cdot p
$$

The average ship's speed can be obtained with the relationship (39).

$$
\left\{\begin{array}{l}
v_{s} \cdot M_{s}=k \Rightarrow v_{s}=\frac{k}{M_{s}}\left\{\begin{array}{l}
v_{s}=\text { the speed of the ship } \\
M_{s}=\text { the mass of the ship }
\end{array}\right. \\
v_{s}=\frac{M \cdot n \cdot N \cdot m_{0}}{M_{s}} \cdot \frac{c \cdot\left(2 \cdot c^{2}-v^{2}\right)}{2 \cdot\left(c^{2}-v^{2}\right)^{3 / 2}} \cdot v
\end{array}\right.
$$

If we note with B the velocity ratio v / c (relationship 30) the expression (39) gets the form (40) and expression (37) takes the new form (41).

$$
\begin{gathered}
v_{s}=\frac{M \cdot n \cdot N \cdot m_{0}}{M_{s}} \cdot \frac{\left(1-\frac{1}{2} \beta^{2}\right)}{\left(1-\beta^{2}\right)^{3 / 2}} \cdot v \\
p=m_{0} \cdot v \cdot \frac{\left(1-\frac{1}{2} \beta^{2}\right)}{\left(1-\beta^{2}\right)^{3 / 2}} \text { when } v \neq c ; v<c
\end{gathered}
$$

Next, one will calculate the acceleration of an elementary particle, which is obtained by means of the system relations (42) knowing that acceleration is practically derived from the impulse in relation to time; where $\mathrm{c}$ is the light speed in vacuum, $\mathrm{h}$ is the Plank's constant and mo is the rest mass of particle.

$$
\left\{\begin{array}{l}
a=\frac{d p}{d t}=\frac{3 p \cdot\left(c^{2}-v^{2}\right)^{1 / 2} \cdot v+m_{0} \cdot c \cdot\left(c^{2}-\frac{3}{2} v^{2}\right)}{\left(c^{2}-v^{2}\right)^{3 / 2}} \cdot \frac{d v}{d t} \text { when } v \neq c ; v<c \\
a-\frac{d p}{d t}=\frac{h}{c} \cdot \frac{d \gamma}{d t} \text { when } v \equiv c ; \text { where } \gamma=\text { particle frequency }
\end{array}\right.
$$


Expression (41) shows that the impulse of an elementary particle moving at very high velocity is amplified compared to the classical impulse known by a factor F (44), and the relation (41) embraces the aspect (43).

$$
\begin{gathered}
p=m_{0} \cdot v \cdot F \text { when } v \neq c ; v<c \\
F=\frac{\left(1-\frac{1}{2} \beta^{2}\right)}{\left(1-\beta^{2}\right)^{3 / 2}}
\end{gathered}
$$

\section{New results}

Next, one will analyze the value of $\mathrm{F}$ in relation to different values of $\beta$ (see the table 2 and expression 44$)$.

It is easy to notice that the first real variations of this factor arise from $\beta=4$.

For a $\beta=7$, the classical impulse is virtually doubled because the amplification factor is 2 .

Beginning with beta 0.99 , the gain factor values increase greatly, so the real (dynamic) impulse becomes much higher than the classic (when elementary particles move at low speeds).

In order to gain a very high impulse boost, it is necessary to accelerate an elementary particle at very high speeds approaching the speed of light. For this reason, it is possible to exploit this phenomenon to unforeseen limits for increasing the impulse of a particle. The current limitation, although smaller than in the past, refers only to the technical possibilities of a particle accelerator (usually circular) to increase their speed to unprecedented limits in the past.

Table 2. Factor $F$ values depending on $\beta$

\begin{tabular}{crr}
\hline $\begin{array}{c}\text { current } \\
\text { number }\end{array}$ & $\beta$ & F \\
\hline 1 & 0.1 & 1.010113764 \\
2 & 0.2 & 1.041883658 \\
3 & 0.3 & 1.100123098 \\
4 & 0.4 & 1.195002732 \\
5 & 0.5 & 1.347150628 \\
6 & 0.6 & 1.6015625 \\
7 & 0.7 & 2.072963654 \\
8 & 0.8 & 3.148148148 \\
9 & 0.9 & 7.184334824 \\
10 & 0.99 & 181.6552616 \\
11 & 0.999 & 5605.548329 \\
12 & 0.9999 & 176825.3106 \\
13 & 0.99999 & 5590323.674 \\
14 & 0.999999 & 176777181.4 \\
15 & 0.9999999 & 5590171485 \\
16 & 0.99999999 & $1.76777 \mathrm{E}+11$ \\
17 & 0.999999999 & $5.59017 \mathrm{E}+12$ \\
18 & 0.9999999999 & $1.76777 \mathrm{E}+14$ \\
19 & 0.99999999999 & $5.59017 \mathrm{E}+15$ \\
\hline
\end{tabular}




\section{Discussion}

In order to gain a very high impulse boost, it is necessary to accelerate an elementary particle at very high speeds approaching the speed of light. For this reason, it is possible to exploit this phenomenon to unforeseen limits for increasing the impulse of a particle. The current limitation, although smaller than in the past, refers only to the technical possibilities of a particle accelerator (usually circular) to increase their speed to unprecedented limits in the past.

If we try to use the relationship (40) to determine the velocity of a ship with its 10-tonne mass for a circular accelerator with a relatively small diameter, which can today easily get a pulse per second $(n=1)$ and an average number of particles per pulse of $(\mathrm{N}) 10^{11}$, considering a single ionic motor $(\mathrm{M}=1)$, it will be obtained for the ship speed $\mathrm{Vs}$, a theoretically calculated value of $28000[\mathrm{~m} /$ $\mathrm{s}]=100800[\mathrm{~km} / \mathrm{h}]$, only at box 19 of table 1 (the last row in table 1), if one can accelerate the elementary particles (here being protons, ie hydrogen ions) up to a beta factor of 0.99999999999 .

This limit of reaching the speed of light, as near as we can actually, allow us to try to accelerate positive ions to unprecedented limits in the past, making future circular particle accelerators an extremely precious tool for humanity. It is possible to obtain very large pulses and energies on the elementary particle, which make the pulse (comprising as many elementary accelerated particles) become a true propulsion jet of modern spacecraft.

The calculations can also be refurbished for high-powered lasers, which additionally have the advantage of being able to produce a lot of pulses per second (even $n=10^{15}$ ).

\section{Conclusions}

Flight is so important to mankind that any type of fuel used from the time, even long before the planet's oil reserves are exhausted, is welcome. Under current conditions, testing and introducing a modernized gas turbine in aviation would be justified because huge reserves of deep-sea shale have been discovered, which today can be exploited thanks to advanced technologies, and gas is already provided for at least a thousand years even if oil reserves are getting smaller). When there will be no more oil and gas, hydrogen will become a major fuel as an inexhaustible fuel, but it can be introduced long before, just to have another source of fuel than the classic fuel, another variant that will guarantee the future and also diminish of consumption of classical fuels that are endangered anyway. The great advantage of using such a system is that we will be prepared to use hydrogen straight away from the water without the need for its storage. This will be possible when modern extraction systems (water dissociation in its components oxygen and hydrogen) will be developed with the use of a lower amount of energy than that obtained by burning hydrogen. This will allow the use of water as an energy storage device.

Today, we can use circular particle accelerators to obtain very large energies in order to achieve controlled nuclear fusion or to make modern propulsions to future spacecraft, with the goal of gaining virtually limitless aircraft autonomy and very fast moving speeds. The paper introduces a new original relationship to determine the particle's impulse when the elementary particle is accelerated at very high speeds close to that of light.

\section{Patents}

!All these Matters are Copyrighted! Copyrights:

1. New Aircraft (New Ionic or Beam Engines): no. 548 of 22-04-2010 [cgiywDssin], Aerospace Engineering

2. Some Few Specifications About the Doppler Effect to the Electromagnetic Waves: 636 of 28-05-2010 [iEtcaouxxA], Physics

3. Presenting an Atomic Model and Some Possible Applications in LASER Field: nr. 639 of 29-05-2010 [yncngrotfo], Physics

4. Some Applications in LASER Field: no. 718 of 09-07-2010 [xeujouincC], Physics

5. The Energies of Today and Tomorrow: nr. 819 of 30-09-2010 [kbHquxwykr], Energy engineering; 
6. Obtaining Energy by the Annihilation of the Matter with Antimatter - The Battle for Energy: nr. 1068 of 13.03.2011 [GfEqpGDzeh], Energy Engineering.

Author Contributions: All the authors contributed equally to prepare, develop and carry out this manuscript.

Funding: This research received no external funding.

Acknowledgments: This text was acknowledged and appreciated by Dr. Veturia CHIROIU Honorific member of Technical Sciences Academy of Romania (ASTR) Ph.D. supervisor in Mechanical Engineering.

Conflicts of Interest: The authors declare no conflict of interest.

\section{References}

1. Langston, L.S., 2016. Hot Plates, Mechanical Engineering magazine, March 2016, pp. 42-27.

2. Langston, L.S., 2015. Gas Turbines-Major Greenhouse Gas Inhibitors, Global Gas Turbine news, in Mechanical Engineering magazine, December 2015, pp. 54-55.

3. Brewer, G.D., Hydrogen Aircraft Technology, CRC Press, Boca Raton, 1991.

4. F. Svensson, A. Hasselrot, and J. Moldanova, "Reduced Environmental Impact by Lowered Cruise Altitude for Liquid Hydrogen-Fuelled Aircraft," Aerospace Science and Technology, Elsevier Science, Vol. 8 Iss. 4, pp. 307-320, June 2004. https://doi.org/10.1016/j.ast.2004.02.004

5. A. Machín, M. Cotto, J. Ducongé, JC. Arango, C. Morant and F. Márquez, 2017. Synthesis and Characterization of Au@TiO2 NWs and their Catalytic Activity by Water Splitting: A Comparative Study with Degussa P25. Am. J. of Eng. and Applied Sci. 10(2):298-311. DOI: 10.3844/ajeassp.2017.298.311

6. Petrescu, F.I.T., 2012. Cold nuclear fusion. Plasma Phys. Fusion Technol., 44: 100-100. https://inis.iaea.org/search/search.aspx?orig_q=RN:44042602

7. Petrescu, F.I.T., Comp. Part. Mech. (2018). https://doi.org/10.1007/s40571-018-0206-7

8. Petrescu, F.I.T. and Calautit, K.J., 2016. About Nano Fusion and Dynamic Fusion, Am. J. Applied Sci. 13(3):261-266. DOI: 10.3844/ajassp.2016.261.266

9. Petrescu, F.I.T. and Calautit, K.J., 2016. About the Light Dimensions, Am. J. Applied Sci. 13(3):321-325. DOI: 10.3844/ajassp.2016.321.325

10. Petrescu, F.I.T., A. Apicella, R.V. Petrescu, S.P. Kozaitis and R.B. Bucinell et al., 2016. Environmental protection through nuclear energy. Am. J. Applied Sci., 13(9):941-946. DOI: 10.3844/ajassp.2016.941.946

11. RVV. Petrescu, R. Aversa, A. Apicella and FIT. Petrescu, 2018. Modern Propulsions for the Aerospace Industry. Am. J. of Eng. and Applied Sci. 11(2):715-755. DOI: 10.3844/ajeassp.2018.715.755

12. FIT. Petrescu, 2018. About the Triton Structure. Am. J. of Eng. and Applied Sci. 11(4):1293-1297. DOI: 10.3844/ajeassp.2018.1293.1297

13. N. Petrescu and FIT. Petrescu, 2018. Elementary Structure of Matter can be Studied with New Quantum Computers. Am. J. of Eng. and Applied Sci. 11(2):1062-1075. DOI: 10.3844/ajeassp.2018.1062.1075

14. RVV. Petrescu, R. Aversa, A. Apicella, MM. Mirsayar, S. Kozaitis, T. Abu-Lebdeh and FIT. Petrescu, 2018. NASA Started a Propeller set on Board Voyager 1 after 37 Years of Break. Am. J. of Eng. and Applied Sci. 11(1):66-77. DOI: 10.3844/ajeassp.2018.66.77

15. RVV. Petrescu, R. Aversa, A. Apicella, MM. Mirsayar, S. Kozaitis, T. Abu-Lebdeh and FIT. Petrescu, 2018. There is Life on Mars? Am. J. of Eng. and Applied Sci. 11(1):78-91. DOI: 10.3844/ajeassp.2018.78.91

16. RVV. Petrescu, R. Aversa, S. Li, MM. Mirsayar, R. Bucinell, S. Kozaitis, T. Abu-Lebdeh, A. Apicella and FIT. Petrescu, 2017. Electron Dimensions. Am. J. of Eng. and Applied Sci. 10(2):584-602. DOI: 10.3844/ajeassp.2017.584.602

17. RVV. Petrescu, R. Aversa, S. Kozaitis, A. Apicella and FIT. Petrescu, 2017. Deuteron Dimensions. Am. J. of Eng. and Applied Sci. 10(3):649-654. DOI: 10.3844/ajeassp.2017.649.654

18. RVV. Petrescu, R. Aversa, A. Apicella and FIT. Petrescu, 2017. Transportation Engineering. Am. J. of Eng. and Applied Sci. 10(3):685-702. DOI: 10.3844/ajeassp.2017.685.702

19. RVV. Petrescu, R. Aversa, S. Kozaitis, A. Apicella and FIT. Petrescu, 2017. Some Proposed Solutions to Achieve Nuclear Fusion. Am. J. of Eng. and Applied Sci. 10(3):703-708. DOI: 10.3844/ajeassp.2017.703.708

20. RVV. Petrescu, R. Aversa, S. Kozaitis, A. Apicella and FIT. Petrescu, 2017. Some Basic Reactions in Nuclear Fusion. Am. J. of Eng. and Applied Sci. 10(3):709-716. DOI: 10.3844/ajeassp.2017.709.716 
21. RVV. Petrescu, R. Aversa, S. Kozaitis, A. Apicella and FIT. Petrescu, 2017. The Quality of Transport and Environmental Protection, Part I. Am. J. of Eng. and Applied Sci. 10(3):738-755. DOI: 10.3844/ajeassp.2017.738.755

22. R. Aversa, RVV. Petrescu, A. Apicella, S. Kozaitis, MM. Mirsayar, T. Abu-Lebdeh, F. Berto, B. Akash and FIT. Petrescu, 2017. Triton for Nuclear Fusion. Am. J. of Eng. and Applied Sci. 10(4):992-1000. DOI: 10.3844/ajeassp.2017.992.1000

23. Petrescu, R.V., R. Aversa, B. Akash, R. Bucinell and J. Corchado et al., 2017. Modern propulsions for aerospace-a review. J. Aircraft Spacecraft Technol., 1:1-8. DOI: 10.3844/jastsp.2017.1.8

24. Petrescu, R.V., R. Aversa, B. Akash, R. Bucinell and J. Corchado et al., 2017. Modern propulsions for aerospace-part II. J. Aircraft Spacecraft Technol., 1:9-17. DOI: 10.3844/jastsp.2017.9.17

25. Petrescu, R.V., R. Aversa, B. Akash, F. Berto and A. Apicella et al., 2017. The modern flight. J. Aircraft Spacecraft Technol., 1:224-233. DOI: 10.3844/jastsp.2017.224.233

26. Petrescu, R.V., R. Aversa, B. Akash, J. Corchado and F. Berto et al., 2017. What is a UFO? J. Aircraft Spacecraft Technol., 1:80-90. DOI: 10.3844/jastsp.2017.80.90 